\title{
REFLEXÕES SOBRE UMA PROPOSTA DE TRADUÇÃO DA PEÇA CATHARSIS, DO DRAMATURGO TOGOLÊS GUSTAVE AKAKPO
}

\author{
Maria da Glória Magalhães dos Reis*
}

\begin{abstract}
Resumo: $O$ presente artigo visa analisar a peça de teatro Catharsis de Gustave Akakpo e refletir sobre as estratégias de sua tradução para o português com base nos conceitos de oralidade e significância desenvolvidos por Henry Meschonnic e Mário Laranjeira e a partir da prática da tradução teatral do diretor e homem de teatro Antoine Vitez.
\end{abstract}

Palavras-chave: Teatro; África; tradução.

"A prática cênica moderna volta a conceder uma grande importância aos textos, e até mesmo à edição de teatro que, durante muito tempo mal das pernas, beneficia-se hoje de uma retomada de atividade e de certa curiosidade em prol dos autores contemporâneos" afirma o teórico de teatro francês Jean-Pierre Ryngaert. ${ }^{1}$ Esse renascimento da dramaturgia contemporânea francesa acontece também com a mesma intensidade nos países de expressão francesa, mais especificamente da África Ocidental. Uma rápida visita pelo site Théâtre contemporain, ou Africultures, ${ }^{2}$

\footnotetext{
* Universidade de Brasília

${ }^{1}$ RYNGAERT. Introduction à l'analyse du théâtre. p. 1, tradução nossa.

${ }^{2}$ Disponível em: http://www.africultures.com/php/. Acesso em: abril de 2010.
} 
ou ainda outros tantos ligados à francofonia, revela uma grande quantidade de autores de origem africana, em cujas obras se observa a vitalidade das novas escritas teatrais, apesar da dura realidade de produção de espetáculos.

Os dramaturgos africanos encenam ora sua revolta diante da mercantilização de seu continente ora seu desespero face à exploração de seus recursos, mostrando igualmente seu ímpeto para a modernidade e criando mitologias particulares em uma língua que renova a percepção que se tem do francês. A escrita teatral contemporânea da África afirma tanto a sua força e a sua determinação literária quanto a sua inventividade estética através de um trabalho formal e lingüístico.

Nesse contexto, chama atenção o Togo, pequeno país francófono, incrustado entre Benin, Gana e Burkina Faso, por duas manifestações culturais que têm feito, já há alguns anos, uma aparição importante na mídia digital. A primeira é a associação Écritures Vagabondes, ${ }^{3}$ criada em 2000 , que reúne dramaturgos e encenadores e tem como missão divulgar autores dramáticos de regiões de culturas minoritárias ou ameaçadas. Em seus nove anos de existência, a associação organizou uma variedade de residências e ateliês de escrita na África, no Oriente médio, na Europa e no Canadá. Esses eventos são concebidos para permitir a autores, vindos de horizontes diversos, trabalharem juntos sobre um tema comum e participarem de ateliês de escrita dramática destinados à formação de jovens autores nas cidades que os acolhem. A segunda manifestação é o FESTHEF (Festival de Théâtre de la Fraternité), que acontece nas cidades de Lomé e Assahoum. O FESTHEF, criado em 1993, agrupa trupes do Togo, da África e da Europa. Seu objetivo é manter uma política de desenvolvimento cultural em termos de criação e divulgação de espetáculos, compreendendo teatro, conto e marionete.

${ }_{3}^{3}$ Disponível em: http://www.ecritures-vagabondes.fr/ Acesso em: 25 de abril de 2010. 
Gustave Akakpo, jovem autor togolês, participou e participa ativamente dessas duas manifestações culturais. Nascido em 1974, em Amého, o autor recebeu, em 1999, seu primeiro prêmio, entre muitos outros, o Plumes Togolaises. Tomou parte de várias residências e ateliês de escrita no Togo, na França, na Bélgica e na Síria. No último deles, no teatro Le Termac de la Villette em Paris, o autor togolês dirigiu, no ano de 2008, ateliês de escrita para detentos. Não tendo nenhuma barreira entre os gêneros literários, Akakpo publica tanto peças de teatro quanto histórias infantis, passando pelo romance. Da tragédia africana à leveza, à comédia, à religiosidade, à irreverência, à vulgaridade mesmo, Gustave Akakpo maneja sua escrita com brilhantismo e originalidade. Lançou-se, inicialmente, na produção de um volume para crianças Querelle au pays de l'alphabet em 2003, publicado em edição bilíngüe éwé e francês. Porém, distingue-se, sobretudo, pela sua determinação em discutir os problemas sócio-culturais da África através de suas peças. Fala das consequências da guerra em La mère trop tôt, de 2004, dos problemas de retorno à terra natal, pior do que o exílio, em Ma Férolia, ainda não publicada, mas representada em festivais em 2004 e 2005, e estabelece um diálogo entre um gângster de rua e uma moça em Demain je sais pas, também inédita.

A sua peça Cathasis, criada em 2006, por ocasião do Festival das Francofonias no Limousin, e dirigida por Jean-Claude Berutti, colocava em cena uma cerimônia teatral bastante instigante. Os espectadores, logo ao entrarem na sala, participavam de um ritual no decorrer do qual deviam deixar bolsas, casacos e sapatos e, até mesmo, deitar-se no chão. Para o diretor, o texto de Akakpo é uma verdadeira peça de guerra na qual as personagens não dizem diretamente os motivos de suas ações, mas murmuramse através de meias palavras o seu sofrimento. A ação acontece em um cemitério, em algum lugar da África, onde uma rainha decaída aceita um ritual de purificação para que a guerra acabe e seu país dilacerado renasça. Construída sobre uma imensa e 
impressionante alegoria, a peça coloca em cena uma cerimônia vodu durante a qual se desenvolve o processo da África através de uma mãe prostituída que negligenciou seus filhos, que se deixou comprar pelo imperialismo dos países ricos e que se arrasta pela sombra com um animal. Seu ritual de purgação simbólica implica o encontro com seus três filhos durante o qual a língua de Gustave Akakpo passa pela exaltação, derrisão, depressão e renascimento.

A rainha Ellè, figura que une ao mesmo tempo a matriarca tirânica, a mãe solteira e a prostituta, encontra, no decorrer da peça, Ilèfou, Ilènoir e Ilèki. Cada um vem para pedir-lhe que preste contas de suas atitudes e para purgar-se de um nascimento fracassado em um continente abandonado. Além da família real, outras duas personagens apresentam o desenvolvimento da trama como uma espécie de coro que, a exemplo de Estragon e Vladimir, de Esperando Godot, de Beckett, representam dois clowns que levam o leitor à derrisão da existência em um reino destruído. $\mathrm{O}$ primeiro deles, o Guardião do Oráculo, espécie de mestre de cerimônias, recebe o público como se este fosse formado pelos chefes de guerra e seus homens. Dirige-se a cada um deles dandolhes nomes bastante expressivos como: o capitão John Way e seus homens, o mollah kamikaze Jacky Chien e até mesmo o francoatirador Zidane. Apesar de seus traços cômicos, o Guardião é quem vai tentar dirigir o ritual de purificação da rainha, trazendo à tona o lado religioso e mítico da peça. Como seu contraponto há o Fotógrafo/Cameraman/Realizador, personagem que representa a modernidade e o capitalismo. Chega carregado de aparelhos fotográficos e de uma câmera com um tripé. Sua entrada em cena, com seus equipamentos, deixa evidente o cômico de sua situação, como um palhaço de circo diante da multiplicidade de seus instrumentos. A primeira coisa que faz é pedir dinheiro. Vai acompanhar e divulgar ao mundo a purgação da mãe África, mas, para isso, precisa receber uma soma em dinheiro, pois, como afirma, sua profissão comporta um grande risco. Assim como o Guardião, o Fotógrafo interpela frequentemente os espectadores. Enquanto 
o primeiro tenta chamar atenção para a seriedade da situação, o segundo pede-lhes que sorriam e façam poses para as fotografias.

A peça é dividida em quatro cenas: La puanteur ("O fedor"), Rite expiatoire ("Rito expiatório"), Le retour ("O retorno") e L'aube ("O amanhecer"). As personagens do Fotógrafo e do Guardião acompanham a personagem principal, Ellè, a rainhamãe, em quase toda a sua trajetória expiatória.

Depois do prólogo, feito pelos mestres de cerimônias, o Guardião chama Ellè e tenta fazê-la sair do fosso onde vive. Durante o diálogo entre os clowns sobre a validade ou não do ritual, a violência, a doença, a escravidão, a rainha começa a sair vagarosamente de seu fosso. Enquanto isso, outra personagem entra em cena, permanecendo na sombra: o único dos três filhos que ficou ao lado a mãe, Ilèfou. Ilèfou também interpela o público. Incomodado com sua presença, pede aos supostos chefes de exército e seus homens para irem embora. O Guardião explicalhe que é preciso que eles fiquem para assistir à catarse. Ilèfou é chamado pelo guardião de príncipe herdeiro, mas o trono de um país destruído não lhe interessa. Nesse momento, entra em cena Ellè. A personagem fala quase o tempo todo na terceira pessoa do singular, como para afirmar sua origem real, com exceção de alguns momentos mais tensos, nos quais se sente ameaçada e passa a falar na primeira pessoa por duas ou três réplicas. Como, por exemplo, no final da primeira cena, em que Ilèfou atinge, sem querer, com um tiro de revólver o Guardião do Oráculo, exatamente no momento de início da dança do ritual expiatório. Quando o Guardião é ferido, Ellè aceita dançar e diz, logo após a rubrica "em choque", "Vou dançar o ritual", repetindo novamente a réplica "Vou dançar o ritual" e em seguida "Eu quero, sim, eu". $\mathrm{Na}$ réplica em francês, ela repete o pronome pessoal je no final da frase: "Oui, je veux, je". ${ }^{4}$ Repetição esta, bastante rara no idioma, no lugar da qual seria preferível o uso do pronome tônico moi

${ }^{4}$ AKAKPO. Catharsis, p. 21, tradução nossa. 
Esse procedimento do autor parece querer mostrar como a personagem ensaia, tenta habituar-se a essa primeira pessoa que não lhe é familiar.

A cena do ritual é um misto de espírito religioso, comicidade e derrisão. O Guardião não pode dirigir o ritual pois está ferido, Ilèfou propõe sua ajuda, assim como o Fotógrafo, que repete as frases finais de Ilèfou, dando o tom de comicidade a toda a cena. Apenas o Guardião e a rainha tentam manter a seriedade da situação. No final, as três personagens adormecem, o que leva a crer que a rainha adormece também, pois, na rubrica, Akakpo escreve que, nas duas cenas seguintes, Ellè sonha com o retorno de seus outros dois filhos.

Ilènoir, o segundo filho, entra em cena no início da terceira parte intitulada $O$ retorno. Ellè demora a reconhecer seu filho, pensa, primeiramente, tratar-se de um cliente, que vem em busca de sexo. Depois de uma réplica em uma linguagem bastante vulgar, com o intuito de expulsar o suposto cliente, Ilènoir diz sua primeira fala: "Desculpe-me...senhora". ${ }^{5}$ Ellè hesita ainda, pensa tratar-se de seu primeiro filho, Ilèfou, mas acaba reconhecendo Ilènoir. Ilènoir é o mais respeitoso dos três irmãos, utiliza o pronome vous, pronome de tratamento formal do francês, no diálogo com a mãe. Ilènoir foi vendido por ela como escravo. Diferentemente de Ilèfou, construiu uma família, mas manteve uma posição subserviente de escravo. Durante todo o diálogo entre eles, Ellè insiste em dizer que ele partira por si mesmo ou ainda que fora levado, no entanto, seu filho insiste em enfatizar que foi vendido pela mãe.

Logo depois da saída de cena de Ilènoir, entra Ilèki, seu terceiro filho, este sim a abandonou, em busca de uma vida melhor. Nessa cena o papel da rubrica é essencial. Ilèki não diz uma única palavra. Segundo o autor "Ilèki abre a boca. Aparentemente fala,

\footnotetext{
5 AKAKPO. Catharsis. p. 32, tradução nossa.

${ }^{6}$ AKAKPO. Catharsis. p. 37, tradução nossa.
} 
mas parece que grunhe" ${ }^{6}$ As indicações cênicas pontuam sua ação: ele ri, afasta-se, aproxima-se, faz sinais com a cabeça. Ellè fala o tempo todo. Em seu quase-monólogo, conta a traição do filho, deixa entender que ele a odeia e que se tornou um dos "estrangeiros do Norte-lá-longe". O "Norte-lá-longe" (Le nord-là-bas) é o lugar que aparece frequentemente no discurso das personagens como o espaço mítico do inimigo. A réplica do filho, ao partir, é repetida pela mãe "Vou chegar lá, lá longe, lá onde escorre o mel. Aqui as moscas brotam de cadáveres que se agarram à vida". ${ }^{7}$ Nessa cena, a personagem principal descreve a vida para um estrangeiro no Norte-lá-longe, evocando temas como a questão do trabalho e da falta de documentos. Durante todo o monólogo da mãe, Ilèki segura um revólver, ri várias vezes, zombando dela e, ao final, atira.

No início do último quadro (O amanbecer), as indicações cênicas são claras "Todos estão na mesma posição do final da cena dois." Ellè e Ilèfou estão cantando. O Fotógrafo e o Guardião acordam. De acordo com o Guardião, a paz finalmente retornou com o amanhecer. No escuro total, ao descer das cortinas, o milagre acontece, ouve-se o choro de um bebê, a rainha-mãe dá a luz, simbolizando o renascimento de seu reino.

A partir desse panorama geral da peça, propomos trazer algumas sugestões de tradução de trechos da peça ${ }^{9}$ e tecer algumas reflexões sobre elas. Tomamos emprestada a afirmação do homem de teatro Valère Novarina "A palavra liberta e ela é também nossa prisão", ${ }^{10}$ para evocar o desafio que a tradução da peça apresenta.

\footnotetext{
7 AKAKPO. Catharsis. p. 39, tradução nossa.

8 AKAKPO. Catbarsis. p. 44, tradução nossa.

9 A peça Catharsis está sendo traduzida pela autora deste artigo com a participação do grupo de teatro En classe et en scène do Departamento de Línguas Estrangeiras e Tradução e de alunos do Departamento de Artes Cênicas, ambos da UnB.

${ }^{10}$ NOVARINA. Voix négative. Entretien avec Valère Novarina, p. ?, tradução nossa.
} 
A palavra, na tradução, liberta, abrindo-se para o estrangeiro, para a língua, a cultura, a literatura e a dramaturgia do outro. Mas, ao mesmo tempo, aprisiona, na dificuldade de expressar, em outra língua-cultura, toda a beleza e intensidade do original. Como traduzir a obra de Akakpo guardando o ritmo de sua linguagem, a oralidade de seu texto, a vulgaridade e a realeza de suas personagens é uma questão que a leitura da peça desperta. Nossa proposta é refletir sobre as principais características do texto Catharsis e em que medida elas interferem no processo tradutório.

Em primeiro lugar, parece interessante ressaltar os nomes das personagens. A personagem principal, Ellè, cuja tradução, em português, seria "Elaé", tem seu nome formado pelo pronome sujeito Elle "Ela" seguido pelo verbo être "ser" na terceira pessoa do singular (est, mas com a escrita è), não havendo complemento de nenhuma espécie. A rainha "é" simplesmente. "Ela é" (Elle est / Ellè). Ela é tudo. "Ela é" a África. "Ela é" a mãe. "Ela é" a prostituta.

O nome de cada um de seus três filhos é formado pelo pronome pessoal sujeito masculino $I l$ "Ele" seguido pelo mesmo verbo ser (est/è), só que cada um dos filhos terá, de acordo com sua personalidade, um complemento que lhe é adequado. $\mathrm{O}$ primeiro, aquele que permaneceu ao lado da mãe o tempo todo, chama-se Ilèfou, ou seja, "Elélouco". Um príncipe herdeiro que não quer herdar o reino de destruição que ora pretende matar o Fotógrafo ora a sua mãe ora matar-se, mas que acaba atirando no Guardião e que dirige um ritual de expiação sem ter certeza de onde isso pode levá-lo. Seu segundo filho, aquele que foi vendido como escravo, é o subserviente, Ilènoir "Elénegro", o que traz a marca da escravidão, da cor da sua pele em seu nome. Seu terceiro filho, Ilèki "Eléquem", é aquele que perdeu suas origens, sua identidade, sem país nem pátria. Parece, portanto, evidente, na tradução da peça, a importância da reflexão sobre os nomes das personagens. A personagem "Elénegro" mostra de maneira bastante contundente a essência de seu nome na réplica: 
La première chose qu'ils te gomment, vous savez? Mon nom, c'est Ilènoir. Un nom que je me suis fabriqué, pour effacer un nom maudit de négrier marqué au fer dans l'âme. Je n'avais pas de nom, lorque j'ai gagné ma liberté. Je suis né noir, j’ai grandi noir, je mourrai noir et on m'appelle homme de couleur, comme si j'étais um caméléon changeant du rouge colère au bleu de peur. Mon nom c'est Ilènoir. ${ }^{11}$

A primeira coisa que eles tiram de você, sabia? Meu nome é Elénegro. Um nome que inventei, para apagar um nome maldito de negreiro marcado com ferro na alma. Eu não tinha nome, quando ganhei minha liberdade. Nasci negro, cresci negro, morrerei negro e me chamam de homem de cor, como se eu fosse um camaleão mudando do vermelho de raiva ao amarelo de medo. Meu nome é Elénegro. (Tradução nossa)

Em segundo lugar, parece essencial, antes de dar continuidade à análise da peça, evocar o conceito de fidelidade na tradução a partir da questão de Henri Meschonnic em Poétique du traduire: fidelidade a quê? Para o autor, a fidelidade deve ser, em primeiro lugar, ao "dualismo da forma e do sentido". ${ }^{12}$ Daí a importância de manter tanto os sentidos que Akakpo expressa como também, a forma, a significância, a oralidade de seu texto. Mostra-se imprescindível, na tradução de um texto teatral, que as réplicas caibam na boca do ator, como se diz no jargão teatral, e como é ressaltado por Meschonnic ${ }^{13}$ ("est bien en bouche") em sua análise das traduções de Hamlet. Para que isso aconteça, a tradução deve priorizar o ritmo e a prosódia, obedecendo à sintaxe oral do original.

\footnotetext{
${ }^{11}$ AKAKPO. Catharsis, p. 36.

${ }^{12}$ MESCHONNIC. Poétique du traduire, p. 89, tradução nossa.

${ }^{13}$ MESCHONNIC. Poétique du traduire, p. 233.
} 
Levando-se em consideração a sintaxe oral das línguascultura de partida e de chegada, um dos grandes desafios é saber até que ponto uma palavra, considerada bastante corriqueira em uma língua-cultura, tem, em seu homólogo na outra língua-cultura, uma expressão extremamente grosseira. É o caso das palavras merde "merda" e foutre "foder": ambas tão usadas no idioma francês que perderam muito do peso que possuíam em seu sentido de origem, ao passo que seus homólogos em português podem ser considerados muito mais grosseiros. Daí a tendência de, principalmente no cinema, freqüentemente traduzirem Merde! por "Droga!" e Je m'en fous por "Não estou nem aí". Pode-se questionar se não existe aqui algum tipo de censura, ou se, pelo contrário, se trataria de uma avaliação da intensidade que cada uma dessas palavras tem nas respectivas línguas-cultura. Porém, a partir desse questionamento, mostra-se essencial ressaltar que a função do tradutor é de reproduzir a linguagem do autor em seu aspecto sonoro e semântico, não cabendo a ele a tarefa de policiar o texto ou tentar poli-lo ou adaptá-lo.

Na peça de Akakpo, por exemplo, "Elaé", no início da cena três, quando fala a seu filho "Elénegro", pensando tratar-se de algum cliente interessado em sexo, começa seu monólogo em um registro bastante familiar, vulgar mesmo:

QUI EST LÀ? QU'EST-CE QUE VOUS VOULEZ? QUI VOUS A LAISSÉ ENTRER? ${ }^{14}$ Revenez demain. Fini pour aujourd'hui. De-main. Tout rangé déjà pour aujourd'hui; boutique fermée; sexe rangé, hormones au dodo. Demain revenez, vous aurez une pipe en prime... ${ }^{15}$

\footnotetext{
${ }^{14}$ A escolha da fonte em caixa alta das três primeiras frases da réplica é do autor do original.

${ }^{15}$ AKAKPO. Catharsis, p. 31.
} 
QUEM É? QUE É QUE VOCÊ QUER? QUEM DEIXOU VOCÊ ENTRAR? Volta amanhã. Hoje acabou. Amanhã. Tudo guardado por hoje; boteco fechado; sexo guardado, hormônios nanando. Amanhã volta, vai ter uma chupadinha de lambuja... (Tradução nossa)

Nessa réplica, podemos refletir sobre dois aspectos, o primeiro, em relação ao uso de termos mais ligados ao registro do oral, e o segundo, em relação ao ritmo do texto, a sua possibilidade de "caber na boca" do ator. No que diz respeito à palavra pipe, cuja tradução literal é "cachimbo" e cujo uso em francês, de conotação sexual, inscreve-se no âmbito da linguagem familiar, apresenta duas possibilidades de tradução em português. A primeira, a palavra boquete, designada pelo dicionário Houaiss como regionalismo e tabuísmo, parece marcada por certo uso marginal. A segunda possibilidade, a palavra chupada, também classificada como tabuísmo pelo mesmo dicionário, inscreve-se também na linguagem familiar, mas, talvez, menos marcada do que a primeira opção e com alusão a duplo sentido como o original pipe. $\mathrm{O}$ uso do diminutivo -inha reforça ainda, em português, o caráter oral do texto. Considerando o segundo aspecto, ou seja, o ritmo, uma tendência natural seria fazer uma tradução quase literal da primeira frase, "QUEM ESTÁ AÍ?", mas o ritmo da fala estaria comprometido, dessa forma, uma opção mais adequada seria “QUEM É?". Para a segunda frase, QU'EST-CE QUE VOUS VOULEZ, há igualmente mais de uma possibilidade:

$$
\begin{aligned}
& \text { QUE É QUE VOCÊ QUER? } \\
& \text { QUE É QUE VOCÊ QUÉ? } \\
& \text { QUÉ O QUÊ? } \\
& \text { TÁ QUERENDO O QUÊ? }
\end{aligned}
$$

Observa-se que a escolha do tradutor vai imprimir um ritmo ao texto, mais ou menos fiel ao original e mais ou menos adaptado ao "dizer" do ator. O tradutor pode ainda fazer uso de algumas marcas da linguagem falada da língua portuguesa como tá, em vez de está, ou qué, no lugar de quer. 
Outro procedimento, bastante característico da obra de Akakpo, que levanta algumas reflexões no que diz respeito à tradução, é a criação de neologismos. O autor cria neologismos instigantes como Americasseurs e Francons, cujas traduções devem manter a originalidade e o ritmo do original. A primeira não apresenta muita dificuldade, sendo feita quase automaticamente como "Ameriquebradores", podendo-se ainda optar por uma fidelidade maior à sonoridade e menos ao sentido, na escolha de "Americaçadores" ou "Americarrascos". No entanto, na tradução de Francons, não parece tão simples encontrar um homólogo perfeitamente adequado ao termo do original. O fato de con ser uma palavra considerada do registro familiar, apesar de apresentar um uso bastante vulgar, referindo-se, em sua origem, ao órgão sexual feminino, é muito utilizada na língua de partida, o que dificulta a descoberta da solução mais adaptada à língua de chegada. Como primeiras opções de tradução, poderíamos pensar em "Franburros" ou "Francoimbecis" que, aparentemente, enfraquecem a expressão de Akakpo, ao passo que, "cuzão", termo não dicionarizado pelo Houaiss, é marcado por um uso mais adolescente, o que daria a expressão "Francuzão" em português. Por outro lado, parece uma boa escolha, levando-se em consideração que há um ganho na manutenção do ritmo e da sonoridade: ambas as palavras são curtas e começam com a letra $c$.

O autor usa ainda, em seu texto, várias enumerações. Um exemplo desse procedimento é observado no início de uma longa réplica do Fotógrafo, na qual a personagem pede dinheiro ao Guardião para documentar o ritual da rainha. Sua fala começa com uma série de termos para referir-se ao dinheiro:

Le blé, l'oseille, le flouze, le maïs, les sous... ${ }^{16}$

Grana, bufunfa, verdinha, dindin, tutu...

(Tradução nossa)

${ }^{16}$ AKAKPO. Catharsis, p. 6. 
Desse exemplo, podem-se tecer os seguintes comentários: em primeiro lugar, a preocupação que o tradutor deve ter com o ritmo da enumeração, observando a quantidade de sílabas das palavras e os tons fortes e fracos; em segundo lugar, é importante sublinhar a questão da supressão do artigo definido que soa muito mais natural na sintaxe oral do português.

Pode-se concluir, então, que traduzir apenas língua, apenas sentidos, não satisfaz, de forma alguma, à necessidade de um texto de teatro. Traduzir é mais do que passar um texto da língua de partida para a língua de chegada, na qual os termos devem ser fiéis ao original e as marcas do tradutor apagadas ao máximo. A tradução deve ser a do discurso, da oralidade, da significância do texto, de acordo com as marcas textuais do autor, sem ignorar que o tradutor também trará as suas nas escolhas que fará, pois, como afirma Mário Laranjeira, "uma tradução só tem vida e valor próprios se for fruto de um trabalho de produção do sujeito, em toda a sua complexidade e não uma simples translação de estruturas semântico-sintáticas". ${ }^{17}$

Em relação ao texto teatral, é preciso também considerar o fato de ele conter em si a potencialidade de sua encenação, isto é, a sua teatralidade gestual, o cenário, o figurino, a iluminação etc. Constata-se, dessa forma, que a tradução de uma peça de teatro deve ser outra peça de teatro, possuindo a mesma oralidade e a mesma teatralidade do texto original. A presença do tradutor enquanto sujeito, que possui sua própria oralidade e que a reinventa a cada nova tradução, mostra que o tradutor é também um escritor. Esse reconhecimento implica na valorização do trabalho do tradutor de teatro como um profissional com conhecimento necessário das duas línguas-cultura, de chegada e de partida, e com compreensão bastante aprofundada do universo teatral.

\footnotetext{
${ }^{17}$ LARANJEIRA. Poética da tradução, p. 124.
} 
Para finalizar, vale ressaltar que não existe uma receita, uma fórmula única para a tradução do texto teatral, cada novo trabalho é um recomeçar. Recomeçar que implica na descoberta de um novo autor com sua oralidade, sua teatralidade, seu discurso, suas marcas. Cada tradução é um mergulho na obra, um trabalho de pesquisa, um deixar-se habitar pelo texto, descobrir sua respiração, para depois, no final do processo, chegar à produção de um novo texto, uma nova peça. Na tradução do texto teatral não se trata de encontrar fórmulas, normas ou regras, mas sim, de estar constantemente em contato com algo dinâmico, paradoxal e dialético que é a linguagem, a oralidade, a teatralidade. As sugestões de tradução propostas no presente artigo estão sendo discutidas e colocadas "em voz" e "em cena" com grupos de alunos especialistas e amadores das artes cênicas e compreendem "respostas passageiras, a serem refeitas, respostas jamais definitivas" 18 como afirma o homem de teatro, diretor e tradutor francês Antoine Vitez que convida o tradutor, em sua obra, a tomar consciência de sua tarefa, sem jamais deixar de admitir o seu caráter provisório e crivado em um determinado conceito histórico e cultural.

Résumée: Cet article vise analyser le texte Catharsis d'Akakpo et réfléchir sur les stratégies de sa traduction vers le portugais basée sur les concepts d'oralité et de signifiance développés par Henry Meschonnic et Mario Laranjeira et à partir de la pratique de la traduction théâtrale du metteur-en-scène et homme de théâtre Antoine Vitez.

Mots-clés: théâtre; Afrique; traduction.

\footnotetext{
${ }^{18}$ DEPRATS. Antoine Vitez, le devoir de traduire, p. 14.
} 


\section{Referências}

AKAKPO, Gustave. Querelle au pays de l'alphabet. Ilustração Kany Adrien Folly et Taofil Adekpodjou, bilingue français/ewe. Paris: L'Harmattan, 2003.

AKAKPO, Gustave. La mère trop tôt. Bélgica: Éditions Lansman, 2004.

AKAKPO, Gustave. Catharsis. Bélgica: Éditions Lansman, 2006.

DEPRATS, Jean-Michel (Org.). Antoine Vitez, le devoir de traduire. Montpellier: Éditions CLIMATS \& Maison Antoinre Vitez, 1996.

LARANJEIRA, Mario. Poética da tradução. São Paulo: EDUSP / FAPESP, 1993.

MESCHONNIC, Henry. Poétique du traduire. Lagrasse: Éditions Verdier, 1999.

NOVARINA, Valère. Voix négative. Entretien avec Valère Novarina. BARCA!, n. 10, p. 149-169, 1998.

RYNGAERT, Jean-Pierre. Introduction à l'analyse du théâtre. Paris: Armand Colin, 2004.

Artigo enviado para publicação em 5 de julho de 2010 . Aprovado em 20 de setembro de 2010. 